\title{
Society for palliative radiation oncology: report from the Seventh Annual Meeting (2020)
}

\author{
Candice Johnstone ${ }^{1}$, Emily J. Martin ${ }^{2}$, Timur Mitin ${ }^{3}$, Yolanda D. Tseng ${ }^{4}$, Jordan Hill ${ }^{5}$, \\ Charles B. Simone II $^{6}$
}

${ }^{1}$ Department of Radiation Oncology, Medical College of Wisconsin, Milwaukee, WI, USA; ${ }^{2}$ Department of Medicine, David Geffen School of Medicine, University of California, Los Angeles, CA, USA; ${ }^{3}$ Department of Radiation Medicine, Knight Cancer Institute, Oregon Health and Science University, Portland, OR, USA; ${ }^{4}$ Department of Radiation Oncology, University of Washington, Seattle, WA, USA; ${ }^{5}$ Department of Radiation Oncology, University of Alberta, Edmonton, Alberta, Canada; ${ }^{6}$ New York Proton Center, New York, NY, USA

Correspondence to: Candice Johnstone, MD, MPH. Department of Radiation Oncology, Medical College of Wisconsin, Milwaukee, WI, USA.

Email: cjohnstone@mcw.edu.

\begin{abstract}
The Society for Palliative Radiation Oncology (SPRO) is an international professional group dedicated to advancing the field of palliative radiation oncology by promoting evidence-based palliative radiotherapy and excellence in primary palliative care through research, education, collaboration, and patient advocacy. SPRO held its $7^{\text {th }}$ Annual Meeting on October 28, 2020 over a virtual platform in association with the American Society for Radiation Oncology (ASTRO) $62^{\text {nd }}$ Annual Meeting. Short and long-term goals for the Society were detailed and the accomplishments since SPRO's $6^{\text {th }}$ Annual Meeting were reviewed. New research was presented during a series of two-minute rapid fire educational sessions given by speakers selected to present in the scientific palliative care track at the ASTRO Annual Meeting. Recipients of the Lifetime Service Award and the Rising Star Award were announced and presented. This Meeting Report summarizes the proceedings of the $7^{\text {th }}$ Annual Meeting and describes future directions for SPRO.
\end{abstract}

Keywords: Palliative radiation therapy; Society for Palliative Radiation Oncology (SPRO); palliative care

Submitted Apr 06, 2021. Accepted for publication May 18, 2021.

doi: 10.21037/apm-2021-03

View this article at: https://dx.doi.org/10.21037/apm-2021-03

The Society for Palliative Radiation Oncology (SPRO) is an international group of clinicians who are passionate about delivering high quality, evidence-based palliative radiotherapy (1). SPRO held its $7^{\text {th }}$ Annual Meeting (and first virtual meeting) on October 28, 2020 in association with the American Society for Radiation Oncology (ASTRO) $62^{\text {nd }}$ Annual Meeting. Building on the goals outlined during the 2019 Annual Meeting (2), approximately 45 attendees (including radiation oncologists, palliative care physicians, residents, and medical students) reflected on accomplishments and established goals for the upcoming year (Figure 1). New, this year, were rapid fire (2-minute) presentations (Table 1) from individuals selected to present for the educational or scientific palliative care track at the ASTRO Annual Meeting. Two SPRO awards were also presented: The Lifetime Service Award and the Rising Star
Award (Table 2).

Dr. Simon Lo presented the SPRO Lifetime Service Award to Dr. Stephen Lutz (Figure 2), a renowned expert in palliative radiation oncology. Dr. Lutz is dual board certified in radiation oncology and hospice and palliative medicine, and he is widely regarded as one of the world leaders in palliative radiotherapy. In addition to founding SPRO in 2014, Dr. Lutz has served in leadership roles for multiple professional organizations, including ASTRO, the American College of Radiology (ACR), the American Society of Clinical Oncology (ASCO), the Radiation Therapy Oncology Group (RTOG), and the American Board of Radiology (ABR). Dr. Lutz has led bone metastases guidelines by ASTRO (4) and ACR (5), and he and has given numerous lectures at prestigious national and international conferences. He has over 100 peer-reviewed 


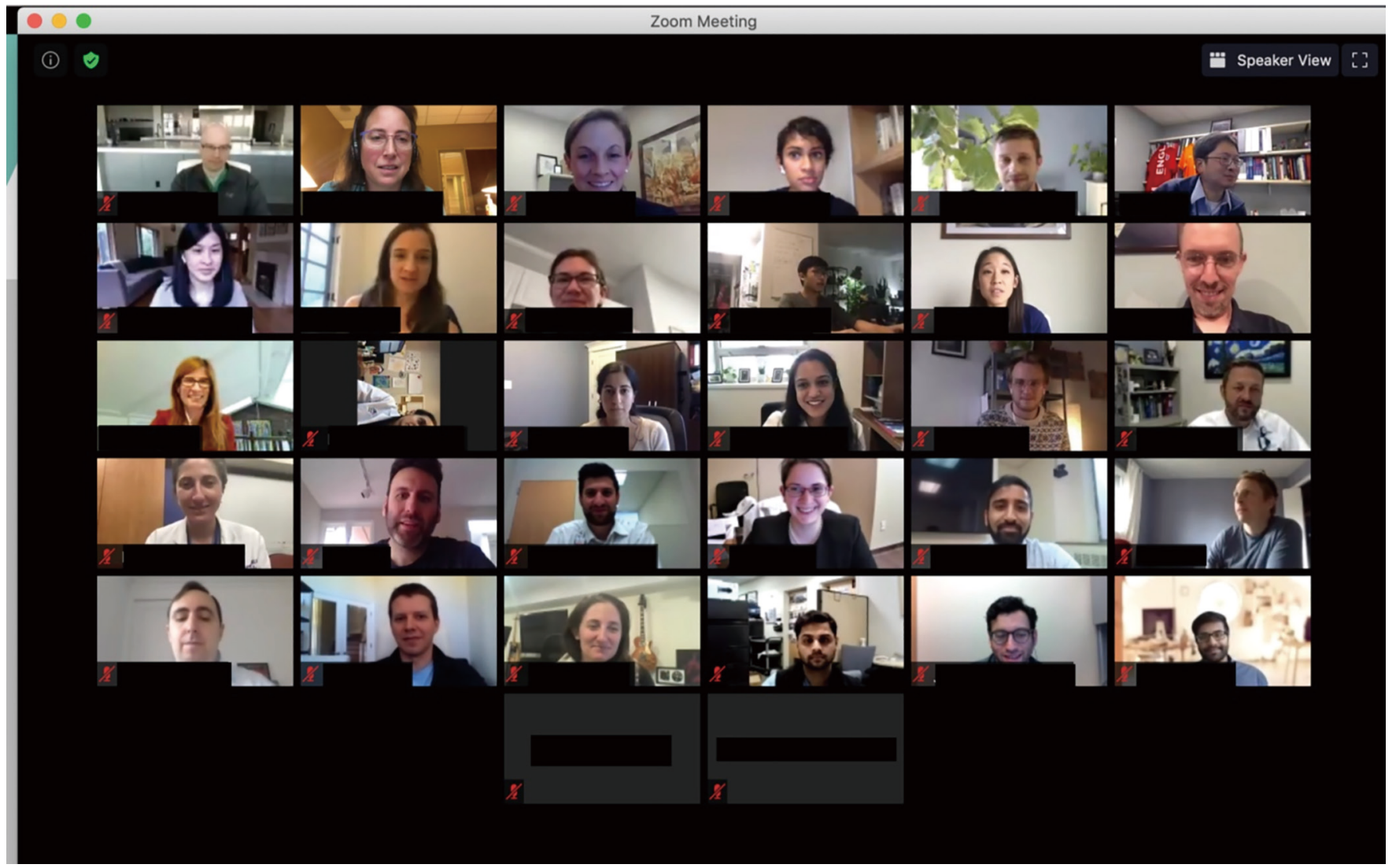

Figure 1 SPRO attendees on zoom.

Table 1 Rapid fire abstract presentations (3)

\begin{tabular}{ll}
\hline Presenter & Title \\
\hline Peter Hoskin & Prognostic factors for survival with metastatic spinal cord compression in the SCORAD randomised trial \\
Tetsuo Saito & Influence of the Pain Duration on Pain Outcomes Following Palliative Radiotherapy for Painful Tumors \\
Anish Butala & The Impact of Provider-Driven Serious Illness Conversations on Length of Palliative Radiotherapy for Bone \\
& Metastases \\
Subha Perni & Predictors of 30-day Mortality Following Palliative Radiation \\
Annie LaVigne & External Validation of the Bone Metastases Ensemble Trees for Survival (BMETS) Machine Learning Model to \\
Improve Estimation of Life Expectancy \\
Susan Wu & Classification of Patients at Imminent Risk of Death at the Time of Palliative Radiotherapy Consultation \\
David Palma & Stereotactic Radiation for the Comprehensive Treatment of Oligometastatic Cancers (SABR-COMET) \\
Long-Term Results & High + Low-Dose Radiation for Metastases Progressing on Immunotherapy \\
Roshal Patel & $\begin{array}{l}\text { Perioperative Radiotherapy for Impending or Pathologic Fractures: Is There a Difference Between Single and } \\
\text { Multifraction Regimens? }\end{array}$ \\
Impact of the COVID-19 Pandemic on Cancer Patients Who Endorse Medicinal Cannabis Use
\end{tabular}


Table 2 Awards

\begin{tabular}{lc}
\hline 2020 Awards & Recipient \\
\hline Lifetime Achievement Award & Steven T. Lutz, MD \\
Rising Star Award & Andrew Bruggeman, MD \\
\hline
\end{tabular}

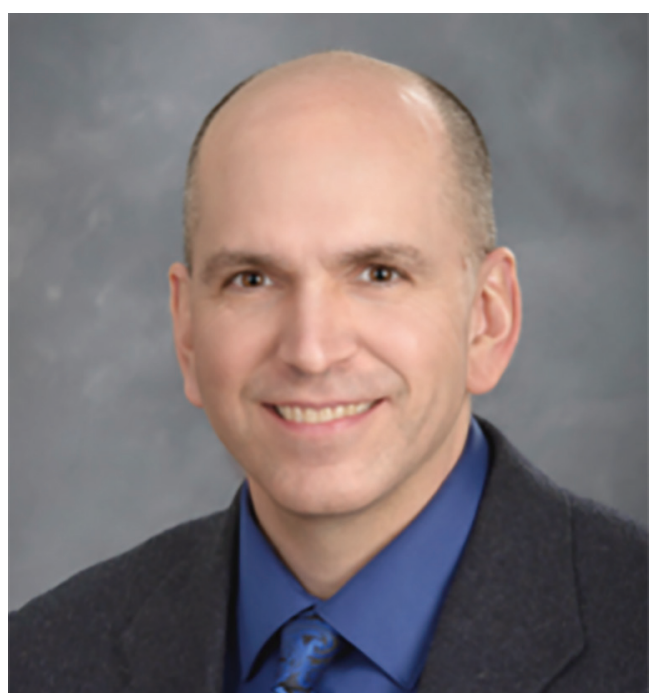

Figure 2 Steven T. Lutz, MD, 2021 Lifetime Achievement Award Recipient.

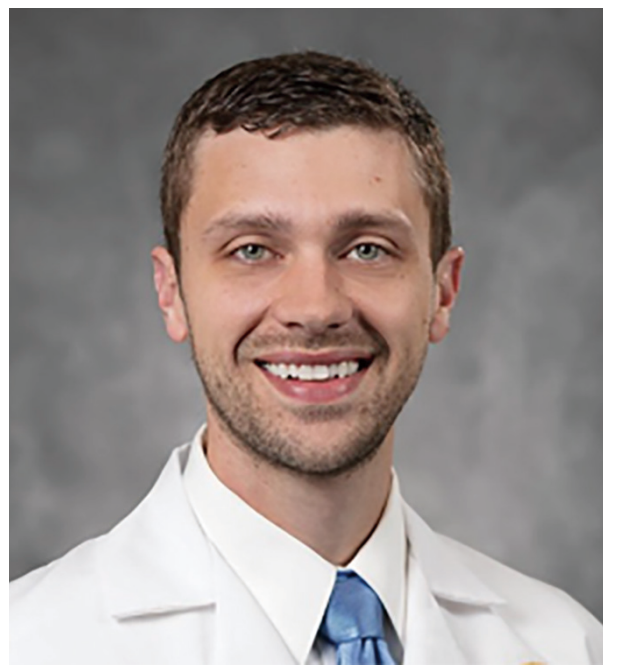

Figure 3 Andrew Bruggeman, MD, 2021 Rising Star Award Recipient.

publications, primarily addressing palliative oncology, palliative radiotherapy, and hospice. Notably, he was named a fellow of ASTRO in 2014.
Dr. Emily Martin presented the SPRO Rising Star Award to Dr. Andrew Bruggeman (Figure 3), a faculty member in the Department of Radiation Medicine and Applied Sciences at the University of California, San Diego (UCSD). Dr. Bruggeman completed residency training in both internal medicine and radiation oncology at UCSD. In July 2019, Dr. Bruggeman joined the UCSD radiation oncology faculty as the Palliative Radiotherapy Section Chief. In this role, he has worked tirelessly to develop a new palliative radiotherapy program - creating departmental guidelines, streamlining palliative radiotherapy workflows, and regularly rounding with the inpatient palliative care service. Although early in his career, Dr. Bruggeman has already made significant contributions to the field of palliative oncology. His recent publications include an evaluation of the utilization of evidence-based prognostic tools among palliative care providers (6), a review article addressing cancer cachexia (7), and a manuscript comparing the toxicity and palliative efficacy of esophageal stenting and palliative radiotherapy for patients with metastatic esophageal cancer (8). Notably, Dr. Bruggeman was awarded the 2018 ASCO Young Investigator Award for his proposal to implement an integrated palliative care clinic in the Department of Radiation Oncology at UCSD.

Dr. Kristopher Dennis presented an overview of the Canadian Palliative Radiation Oncology Group (CPROG), a network of clinicians with an interest in palliative radiotherapy and supportive care. CPROG hosts monthly virtual meetings featuring short presentations and lively discussions on topics relevant to palliative radiation oncology and supportive care. It is a forum to discuss palliative educational initiatives and research proposals, hear about ongoing and recently published studies, participate in case-based clinical discussions and network with similarly interested clinicians and trainees. CPROG now formally resides under the administrative umbrella of the new Supportive Care Committee of the Canadian Association of Radiation Oncology (CARO). Individuals interested in participating in CPROG are encouraged to contact the corresponding author.

Dr. Chuck Simone, Editor-in-Chief of Annals of Palliative Medicine (APM), highlighted recent accomplishments of APM. Since the open-access peer review journal was launched in 2012, APM has become indexed in PubMed, Medline, Scopus, and SCIE. The journal received its first impact factor in 2019 (9), which has increased in the following years. APM includes a Palliative Radiotherapy Column co-edited by Drs. Edward Chow and Candice 
Johnstone.

Dr. Divya Yerramilli from Memorial Sloan Kettering Cancer Center highlighted practical questions pertaining to the management of patients with advanced cancer. These include how to approach systemic therapies that may temporally overlap with palliative radiotherapy and the role and extent of post-radiotherapy surveillance protocols. These topics were discussed in small group breakout rooms and next steps were outlined.

Due to the success of the virtual format, SPRO will be holding quarterly virtual meetings to further our efforts. Please contact SPRO or the corresponding author to suggest a topic or talk for these quarterly meetings. The Annual Meeting Committee will be responsible for curating content and welcomes additional volunteers.

Goals were developed for the coming year. SPRO is in the final stages of obtaining non-profit status, which should be established before the end of 2020. We discussed the structure of the committees, current membership of the committees, and ongoing need for additional volunteers (please contact admin@spro.org for details). The current five committees include membership, annual meeting, finance, awards, and communication. Once SPRO has achieved non-profit status, members will be notified about dues, which are a requirement for active membership. These dues will fund the application for non-profit status and ongoing expenses related to being a non-profit society, ensure continued funding for awards and other SPRO activities. A call for nominations for the Lifetime Service and Rising Star Awards will be announced in Summer 2021. The Palliative Radiotherapy Column published in Annals of Palliative Medicine has been reinvigorated and we will update our website (www.spro.org). New ideas and members are always welcome! Contact the corresponding author or admin@spro.org by email.

\section{Acknowledgments}

Funding: None.

\section{Footnote}

Conflicts of Interest: All authors have completed the ICMJE uniform disclosure form (available at https://dx.doi. org/10.21037/apm-2021-03). CJ serves as the Chair of Palliative Radiotherapy Subcommittee of Annals of Palliative Medicine from Jul 2019 to Jun 2021. YDT serves as an unpaid editorial board member of Annals of Palliative Medicine from
May 2019 to Apr 2021. CBS 2nd serves as the Editor-inChief of Annals of Palliative Medicine. The other authors have no conflicts of interest to declare.

Ethical Statement: The authors are accountable for all aspects of the work in ensuring that questions related to the accuracy or integrity of any part of the work are appropriately investigated and resolved.

Open Access Statement: This is an Open Access article distributed in accordance with the Creative Commons Attribution-NonCommercial-NoDerivs 4.0 International License (CC BY-NC-ND 4.0), which permits the noncommercial replication and distribution of the article with the strict proviso that no changes or edits are made and the original work is properly cited (including links to both the formal publication through the relevant DOI and the license). See: https://creativecommons.org/licenses/by-nc$\mathrm{nd} / 4.0 /$.

\section{References}

1. Wei R, Simone CB 2nd, Lutz S. Society for palliative radiation oncology: founding, vision, and report from the Second Annual Meeting. Ann Palliat Med 2016;5:74-5.

2. Martin E, Tseng Y, Simone CB 2nd, et al. Society for Palliative Radiation Oncology: report from the sixth Annual Meeting [2019]. Ann Palliat Med 2020;9:2420-3.

3. Zietman A. (Eds). Proceedings of the American Society for Radiation Oncology. Int J Radiat Oncol Biol Phys 2020;108:e1-e929.

4. Lutz S, Berk L, Chang E, et al. Palliative radiotherapy for bone metastases: an ASTRO evidence-based guideline. Int J Radiat Oncol Biol Phys 2011;79:965-76.

5. Janjan N, Lutz ST, Bedwinek JM, et al. Therapeutic guidelines for the treatment of bone metastasis: a report from the American College of Radiology Appropriateness Criteria Expert Panel on Radiation Oncology. J Palliat Med 2009;12:417-26.

6. Bruggeman AR, Heavey SF, Ma JD, et al. Lack of documentation of evidence-based prognostication in cancer patients by inpatient palliative care consultants. J Palliat Med 2015;18:382-5.

7. Bruggeman AR, Kamal AH, LeBlanc TW, et al. Cancer cachexia: beyond. weight loss. J Oncol Pract 2016;12:1163-71. 
8. Martin EJ, Bruggeman AR, Nalawade VV, et al. Palliative radiotherapy versus esophageal stent placement in the management of patients with metastatic esophageal cancer. J Natl Compr Canc Netw 2020;18:569-74.

Cite this article as: Johnstone C, Martin EJ, Mitin T, Tseng YD, Hill J, Simone CB 2nd. Society for palliative radiation oncology: report from the Seventh Annual Meeting (2020). Ann Palliat Med 2021;10(6):7146-7150. doi: 10.21037/apm-2021-03
9. Simone CB 2nd. Annals of Palliative Medicine earns its first official impact factor. Ann Palliat Med 2019;8:352-4. 